\title{
Surrealismo, género y ciudad en la obra pictórica y poética de Remedios Varo
}

\author{
Anna F. VIVES \\ School of Modern Languages \\ University of Leicester (Reino Unido) \\ anna.vives@le.ac.uk
}

Recibido: $15 / 03 / 2013$

Modificado: $05 / 05 / 2013$

Aceptado: $11 / 05 / 2013$

\section{Resumen}

Como indican Roger Caillois (1969), Octavio Paz (1969) y Eugenio F. Granell (1989), la obra pictórica de Remedios Varo está repleta de espacios liminares (de umbrales literales y no literales) que son representativos de la plenitud cósmica. En estos espacios, relativamente fieles a los principios del segundo manifiesto surrealista (1930) y enlazados por la seducción mutua o por una simple continuidad ineludible, se perfila una transición entre lo natural y lo urbano y una particular manera de apreciar la ciudad. La liminalidad en la obra pictórica y poética de Varo responde a una necesidad de crear un espacio nuevo para el sujeto femenino, un espacio contestatario que rompe con la tradicional dualidad objeto/sujeto para presentarse como entidad fluctuante y plurivalente. He aquí que lo maravilloso desemboca en heterotopía. En definitiva, el continuum de objeto/sujeto en la obra de Varo determina una visión no convencional de lo urbano.

Palabras clave: Remedios Varo, liminalidad, surrealismo, heterotopía, género.

Title: Surrealism, Gender and City in the Pictorial and Poetic Work of Remedios Varo

\section{Abstract}

According to Roger Caillois (1969), Octavio Paz (1969) and Eugenio F. Granell (1989), the pictorial work of Remedios Varo is full of liminal spaces (both literal and metaphorical) that represent cosmic plenitude. In these spaces, relatively faithful to the principles of the second Surrealist manifesto (1930) and linked by a mutual seduction or by a simple unavoidable continuity, one can perceive a transition between the natural and the urban as well as a particular way of appreciating the city. Liminality in Varo's paintings and poems respond to a necessity of creating a new space for the feminine subject, a non-conformist space that breaks with the traditional opposition object/subject to present a fluctuating and multivalent entity. It is in this way that the marvellous leads to the heterotopic. In short, the continuum of object/subject in Varo's work encapsulates an unconventional image of the urban.

Keywords: Remedios Varo, liminality, Surrealism, heterotopia, gender. 


\section{Índice}

1. El umbral, lo maravilloso, la heterotopía y la after-image

2. La liminalidad

2.1. La liminalidad en la obra pictórica y poética de Varo

3. Análisis de Tránsito en espiral

3.1. La ciudad

3.2. La espiral, la insularidad y el barco

4. La androginia y el tiempo

5. Conclusiones

\section{El umbral, lo maravilloso, la heterotopía y la after-image}

Este artículo versa sobre el surrealismo, el género y la ciudad en la pintura y la poesía de Remedios Varo (1908-1963) ${ }^{1}$, haciendo hincapié en la presencia de espacios liminares (de umbrales literales y no literales) que pueblan su obra. El umbral es un símbolo tanto de la separación como del potencial de amistad, casamiento o reconciliación (Chevalier y Gheerbrant 1996: 997). En referencia al último significado, que es el que más interesa en conexión con la estética variana, el umbral tiene una naturaleza feminoide, una naturaleza que nos lleva a las teorizaciones de Luce Irigaray sobre el carácter fluctuante e inclusivo del género femenino (1985: 106-18) ${ }^{2}$. Por otro lado, no dejan de ser relevantes los manifiestos de André Breton, donde se alerta que la actividad surrealista permite la yuxtaposición de dos realidades diametralmente opuestas (como la de la noche y el día, que se unirían en una noche llena de relámpagos), gracias a la naturaleza ilimitada del deseo (Breton 1972a: 37-38), y que el surrealismo pone en comunión el sueño y la vigilia, la vida y la muerte, lo real y lo imaginario, el pasado y el futuro, lo comunicable y lo incomunicable, lo alto y lo bajo (Breton 1972b: 123). Como se verá a través de ejemplos pictóricos y poéticos, Varo nos ofrece ciudades fuera de lo común que participan de estas dualidades: se trata de metrópolis que desembocan en lo natural, o de naturaleza que conduce a calles medievales de ensueño, como en el caso de Coincidencia de $1959^{3}$. Pero estos espacios maravillosos no parecen encasillarse exclusivamente bajo las teorías bretonianas. Según Breton, sólo lo maravilloso es bello (1972a: 14).

1 Jaume Fàbrega (1988: 43) da 1913 como año de nacimiento de Varo, lo que constituye un error. Lo mismo ocurre en el caso de Joan-Josep Tharrats (1993: 127). Sin embargo, como indica Eva Vàzquez (2004: 2), fue sólo en 1991 que se corrigió este error y hay que añadir que el breve ensayo que Tharrats escribiera sobre Varo fue redactado en julio de 1987.

2 Estas páginas remiten al capítulo "The 'Mechanics' of Fluids".

3 En Janet A. Kaplan (2000: 211). De ahora en adelante se hará referencia a este volumen en el cuerpo del artículo, ya que la mayoría de pinturas de Varo que menciono aparecen aquí. Si bien el Catálogo Razonado editado por Walter Gruen y Ricardo Ovalle y publicado por primera vez en 1994 (México: Ediciones Era) sería el punto de referencia oficial, el libro de Kaplan se puede consultar con más facilidad. 
Más en particular, define lo maravilloso como cualquier símbolo capaz de afectar la sensibilidad humana por un período de tiempo. Se trata de aquellos elementos cuya influencia no nos deja indiferentes, como dice Breton, aquellos que nos ponen una sonrisa en la boca (1972a: 16). Ahora bien, esta sonrisa puede ser provocada tanto por actos morales como por actos inmorales, he aquí el espíritu de desmoralización del surrealismo (1972a: 17).

Aunque la sorpresa ante lo vehemente y la posibilidad de desmoralización puedan conferir al arte de Varo la etiqueta de maravilloso, parece que aquello que prima en su obra es el carácter heterotópico de los espacios. En Varo, lo maravilloso sería el camino a través del cual la protesta inherente a la heterotopía se perfila, pues los suyos son espacios contestatarios que abren nuevos caminos para contemplar el espectáculo de la ciudad ${ }^{4}$. Hay que recordar que para Michel Foucault las heterotopías son lugares que contestan los espacios controlados y regulados en los que normalmente estamos inmersos, y también incluye en esta definición la creación artística de espacios ilusorios (Foucault 1994: 755). Por mucho que se parezcan a las utopías, las heterotopías y éstas solamente encuentran un espacio liminar a través de la experiencia del espejo. El espejo es una utopía ya que puedo verme a mí misma allí donde estoy ausente, pero también es una heterotopía pues pertenece a la realidad y confirma la existencia del espacio físico que ocupo (Foucault 1994: 756). Foucault añade que es posible contar simultáneamente con una contestación mítica y real del espacio en el que vivimos (Foucault 1994: 756). Por otro lado, las heterotopías guardan relación con las sinécdoques y en este sentido Foucault menciona que "le jardín, c'est la plus petite parcelle du monde et puis c'est la totalité du monde". Toma como base el jardín de la cultura persa, el cual solía representar las cuatro partes del mundo (Foucault 1994: 759). Éstas son algunas de las características de las heteropías que se aprecian en Varo.

Aparte de los conceptos de lo maravilloso y lo heterotópico, la idea de after-image de Joan Ramon Resina resulta iluminadora. Resina argumenta que el acto de observar la ciudad resulta en un número de after-images más que de imágenes, porque las primeras incluyen la temporalidad que envuelve constante y frenéticamente a la realidad (Resina 2003: 10). Teniendo en cuenta esta imposibilidad

\footnotetext{
${ }^{4}$ Estrella de Diego (2007: 67) considera que el surrealismo de Varo, una vez se instala en México, es dudoso. Es decir, el movimiento liderado por Breton no es la única referencia que debemos tener en cuenta al aproximarnos a la obra de la artista, sino que, como dice De Diego, "lo que se hace patente en la obra de Varo es la comentada esencia de México con lo que tiene de híbrido y de mezcla, de cierto panteísmo y esa magia que inundan toda la producción de la artista" (2007: 74).
} 
de aferrarse al pasado, la after-image siempre implica una realidad representacional diferente a la que pudimos percibir en otro momento. De hecho, la after-image cobra sentido al reconocerse la desaparición de la imagen original (Resina 2003: 13). Las posibilidades teóricas de tal concepto se explorarán en relación a los lugares en los que Varo pasara parte de su vida. En este sentido, parece importante el barrio gótico de Anglès "reclòs i llòbrec, de múltiples arcades i escales tortuoses" (Vàzquez 2004: 5). Joan-Josep Tharrats (1993: 129-30) comenta que "des de la seva nostàlgia, Remei Varo veia el carrer d'Amunt i el carrer d'Avall, d'Anglès, i els poblava d'objectes volants que neguitejaven l'entrada en els vells finestrals ogivals". Estrella de Diego también remarca la presencia del espacio ocupado en el pasado en la obra variana, presencia que resume como "rastros arquitectónicos de la infancia -espacios del románico-" (De Diego 2007: 114). Entre las imágenes que Varo vio en persona en su Anglès natal, y en Gerona en general, y las que dejó en su obra existen diferencias: no son los mismos edificios sino que se basan en ellos, son las ideas de aquella arquitectura. He aquí el concepto de la after-images.

\section{La liminalidad}

El estudio de la obra de Varo nos muestra que la ciudad no tiene que ser un espacio representado cúbica y estáticamente, existen otras formas alternativas de plasmar la urbe. Por ejemplo, se verá que los espacios liminares son importantes en la imagen de la ciudad que nos ofrece la artista. Además, la idea del umbral también está en sintonía con la biografía de Varo: una mujer que vive en España y Marruecos antes de sufrir un doble exilio a Francia y México. Una mujer que es vista por los surrealistas como musa ${ }^{5}$, con todo lo que ello conlleva de objetivización y denigración de su autoría artística. Las ideas de frontera, cruce, limen pueblan la obra de Varo e informan la naturaleza de sus ciudades. Como indica Janet Kaplan, Varo "va aprendre a navegar pels marges per la seva condició doble de dona i expatriada, i a extreure la seva força creativa d'aquesta excepcionalitat marginal" (apud Vàzquez 2004: 3). Por supuesto, no se quiere caer en la reducción de la figura de Varo a un mero vaivén de los elementos, sino más bien poner de manifiesto que esta autora vivió su vida desde la exclusión.

${ }^{5}$ Esta idea de la mujer como musa de los surrealistas la explora Whitney Chadwick (1985). Kathryn A. Everly también incide en el mismo problema (2003: 23-24). 


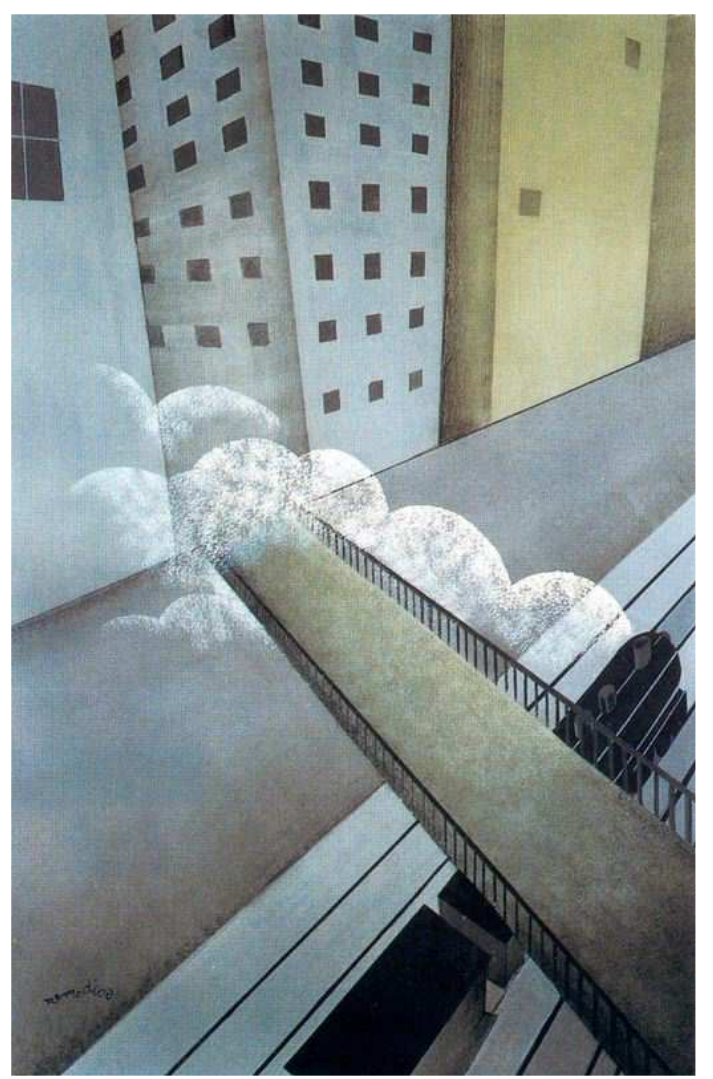

Figura 1. Modernidad (1936) (c) Remedios Varo, DACS/VEGAP, 2013.

En Varo la imagen de la ciudad no remite a la representación fotográfica de urbes contemporáneas como, pongamos por caso, Nueva York, a excepción del caso de Modernidad (1936) (figura 1). En esta obra, que recurre principalmente a colores entre el gris y el marrón, se aprecian unos edificios altos, una calle, un puente y, bajo éste, un tren que cruza el paisaje y lo llena del humo que surge de la locomotora. En definitiva, una imagen prototípica de las implicaciones de la modernidad en la primera parte del siglo XX. Pero por lo general, sus pinturas y poemas incluyen ciudades situadas en otros tiempos y espacios $y$, en ocasiones, elementos (sinecdóticos) que apuntan sutilmente a lo urbano. En The Sphinx in the City, Elizabeth Wilson observa que la ciudad de París del siglo XIX era un objeto de deseo y, en concreto, una mujer. La idea subyacente es que la ciudad podía tomarse como un objeto de deseo de naturaleza femenina: "Above all, Paris was the city sexualised. Poets sometimes likened Paris to a prostitute, but more often sang her praises as a queen [...]. Either way, the city was inescapably female" (Wilson 2002: 419) ${ }^{6}$. Las ciudades de Varo contestan esta concepción del fenómeno urbano, no son como el París del que habla Wilson: no son objetos de

${ }^{6}$ Chevalier y Gheerbrant apuntan que, según el psicoanálisis contemporáneo, la ciudad es relativa al principio femenino (1996: 204). Se vuelve sobre esta idea más adelante, al analizar Tránsito en espiral (1962). 
deseo (al menos no solamente) sino espacios-sujetos activos que guardan una relación orgánica con el otro y no adoptan una postura pasiva. Las barreras entre objeto y sujeto se difuminan en la obra de Varo. Esto se consigue de varias formas: por la aparición de sujetos andróginos, por el continuum que se establece entre seres vivos y por la sensación de integración del espectador/lector en las imágenes y poemas a causa de la proliferación de puertas, ventanas y otras formas de acceso.

\subsection{La liminalidad en la obra pictórica y poética de Varo}

La relación entre el cuerpo y la ciudad es bastante frecuente en las manifestaciones artísticas del modernismo y Varo no es una excepción. En Como en un sueño (1938) (Kaplan 2000: 60), una especie de ondulante carretera y un cuerpo de mujer están en perfecta simbiosis ${ }^{7}$. Además, aquí también se observa, como dice Eugenio F. Granell (1988: 66), que "no hay límites entre monte y calle". Octavio Paz explica esta idea diciendo que en Varo "el espacio no es una extensión sino el imán de las Apariciones" (Varo 1969: 9); y Roger Caillois se expresa de modo similar: "La arquitectura y la naturaleza aparecen en frecuente simbiosis [...] existe [...] una continuidad en el paisaje, la arquitectura, la vegetación" (Varo 1969: 18 y 24). Esta idea es de suma importancia para entender la esencia de la ciudad de Varo, que sintoniza con la advertencia de Gaston Bachelard sobre la necesidad de mantener viva la relación entre la arquitectura y la naturaleza:

A la ausencia de valores íntimos de verticalidad hay que añadir la falta de cosmicidad de la casa de las grandes urbes. Allí las casas ya no están dentro de la naturaleza. Las relaciones de la morada y del espacio se vuelven ficticias. Todo es máquina y la vida huye por todas partes. Las calles son como tubos donde son aspirados los hombres. (apud Luquin 2008: 193)

Gilbert Durand concibe la casa, igual que Arthus, Minkowska y Fusswerk, como un punto medio entre el cosmos y el microcosmos del cuerpo humano cuya iconografía tiene importantes implicaciones desde el punto de vista psicológico y psicosocial. Y para clarificarlo utiliza una cita freudiana: "Tell me the house you imagine, and I shall tell you who you are" (Durand 1999: 235). La casa, dice Durand a

\footnotetext{
${ }^{7}$ Andrea Luquin Calvo lee esta obra como ejemplo de violencia de género, donde "a la mujer la están estirando, como en una especie de tortura medieval, en un árido paisaje" (2008: 333). También se ha entendido la ausencia de cabeza como un énfasis en la sensualidad y corporalidad de la mujer en detrimento de sus cualidades intelectuales. Este tema se discutió el 5 de noviembre de 2010 durante el simposio "Límenes maravillosos: una jornada dedicada a Remedios Varo", que tuvo lugar en Queen's University Belfast.
} 
partir de Baudouin, es tanto corporal como mental (Durand 1999: 235). La casa es un ser vivo (Durand 1999: 236). En muchas ocasiones, la obra de Varo presenta la arquitectura y la naturaleza como partes de un mismo cosmos, como en Armonía (1956) y Visita al pasado (1957), donde del suelo de la morada emerge una arraigada vegetación ${ }^{8}$. O como en Arquitectura vegetal (1962) (Kaplan 2000: 190, 148 y 188 respectivamente), pintura que por otro lado se hace eco de las escaleras, perspectivas y ventanas que pueblan el arte de Maurits Cornelis Escher, por ejemplo el grabado Covered Alley in Atrani, Amalfi (1931) (cfr. Johnson 2013).

Esta relación entre la arquitectura y la naturaleza aleja la obra de Varo de la producción de algunos de sus contemporáneos. Por ejemplo, en el poema La nature dévore le progrès et le dépasse (1937) de Benjamin Péret, con quien estuvo casada, la selva cual "mujer amada" es capaz de seducir con "gestos provocativos y miradas incitantes" al hacha, a la dinamita, al tren y al mismo maquinista, es decir, al progreso. La naturaleza se impone a la máquina, la devora (Granell 1988: 66). Otro ejemplo es la novela Sister Carrie (1900) de Theodore Dreiser, donde se destaca el poder de seducción de la ciudad: "The city has its cunning wiles, no less than the infinitely smaller and more human tempter [...]. The gleam of a thousand lights is often as effective as the persuasive light in a wooing and fascinating eye" (Dreiser 1970: 1). Varo se situaría entre las posturas de Dreiser y de Péret, pues en ella la naturaleza y la ciudad tienen un poder de atracción similar.

La poesía de Varo resulta iluminadora por lo que respecta a la imagen de la ciudad. Por ejemplo, en su Sueño 5 se hace hincapié en la manera de observar la urbe:

Estábamos Eva [Sulzer] y yo en mi casa, en la sala. Era esta casa, pero, sin embargo, diferente a como es. Por la ventana se veía la avenida, que era muchísimo más ancha. Los edificios de enfrente estaban algo lejos. Mirábamos por la ventana y, de repente, Eva me dijo: "Ah, [Wolfgang] Paalen acaba de entrar en ese hotel de ahí enfrente" (en realidad, no hay ningún hotel). (Varo 1999: 124)

En este fragmento, que es una recreación onírica del espacio metropolitano, se aprecia una distorsión de la magnitud, la distancia y la realidad misma de los elementos urbanos. Es interesante la naturaleza surrealista del extracto, pero también la posición de la voz poética como sujeto observador. Entre una visión que rememora el pensamiento de Guy Debord y una visión foucaultiana, aquello que se

${ }^{8}$ La representación de la casa se da con mucha frecuencia en Varo, frecuencia que, según Durand, se relaciona con el apego emocional a la patria (1999: 261). Así pues, se podría estudiar la relación entre arquitectura y exilio en la obra variana. 
observa implica simultáneamente un espectáculo y un acto de vigilancia9. También así puede entenderse un fragmento onírico de su proyecto de obra de teatro, donde la doble experimentación del espectáculo y la vigilancia implican vivir la ciudad de modo alternativo:

Me ofreció uno [cigarrillo] y me llevó con él hasta un balcón. Entonces, prendió su cigarro y el mío y me instó a que soplase el humo contra la lluvia. Así lo hicimos, y vi con sorpresa que este humo tenía la propiedad de endurecer repentinamente las gotas de agua, que caían como una lluvia de piedrecillas sobre la gente que pasaba por la calle. Él se divertía mucho y, de vez en cuando, se retiraba al interior para poder reír a carcajadas. Yo vi que se formaba un grupo de gente furiosa que se lanzaba dentro de la casa, seguramente para llegar hasta nosotros. Y entonces, ustedes me han despertado, icuánto me alegro! (Varo 1999: 102)

La contemplación del Sueño 5 ocurre a través de la ventana, como se ha leído más arriba, pero también "asomándome a una especie de balcón" y "desde el balcón de mi casa" (Varo 1999: 124). Además, resulta curioso que cada vez que se menciona el balcón se incide en el hecho de que "no existe en realidad", pero ¿por qué remarcar a cada paso las diferencias entre sueño y realidad si el título ya deja claro que se trata de un sueño? Es posible que tal insistencia, un tanto mecánica, guarde relación con la manera en que se producen los sueños según Varo: para soñar hay que estar conectado a un mecanismo a base de poleas que recoge la energía de los astros $^{10}$. Curiosamente, los sueños de Varo no son totalmente ajenos al mundo de la ciencia. Tal comunión de opuestos es importante en su percepción de la ciudad ideal, algo que se explorará con más detalle en Tránsito en espiral.

Antes mencionábamos que no hay un corte claro entre monte y calle. Pues bien, tampoco lo hay entre la experiencia de la embarcación y la calle del Sueño 6. Además, dicho sueño también recalca la idea del exilio como tránsito infinito, no sólo por el continuum indicado sino también porque aparece un maremágnum de nacionalidades y lugares:

[L]legamos a Londres. Quisimos desembarcar en seguida, pero a la salida del barco comenzaba inmediatamente una calle y allí había un

9 Davide Deriu (2006: 191) se refiere a las visiones encontradas por lo que respecta a los modelos conceptuales del funcionamiento de la sociedad a partir del panóptico y el panorama, sugiriendo que reducirse a la perspectiva de Foucault sobre la sociedad disciplinaria o a la perspectiva de Guy Debord sobre la sociedad del espectáculo no refleja la complejidad de las técnicas de visión total en lo que concierne a la sociedad moderna.

${ }^{10}$ Esta concepción de lo onírico se aprecia en su obra Sueño (1958). 
gendarme de tránsito que me pidió mis papeles y, como no los tenía, no me dejaba pasar [...] junto al barco, estaba la terrasse de un café y que allí había tres mujeres con aspecto mexicano hablando en español. (Varo 1999: 126)

En Varo, el elemento urbano forma parte de un universo donde todo queda relacionado. Así pues, el espacio en una obra como Presencia inquietante (1959) (Kaplan 2000: 158) se podría tomar como el interior de una casa, pero también como un paisaje ciudadano con sus callejones y sus estructuras verticales: en esta pintura no hay un techo que limite esta posibilidad, hay un pasadizo de aspecto laberíntico y de una mesa de madera emergen ramas finas y amarillentas que mantienen viva la conexión entre lo inerte y lo vivo y entre dentro y fuera. Además, para Walter Gruen, Presencia inquietante está relacionada con el Sueño 9 (Varo 1999: 131), donde la dificultad de separar lo exterior y lo interior queda remarcada: "comprendí que no era verdad el haber oído ese ruido peligroso arriba, pero que yo había en cierto modo querido oír esa amenaza fuera y arriba, pero que en realidad estaba siempre junto a mí o en mí" (Varo 1999: 131).

También es de interés el Sueño 10, donde la ejecución de la protagonista tiene lugar en un espacio liminar: "El verdugo me llevó a un lugar que parecía como la muralla de una ciudad. De cada lado de la muralla, bajaba una pendiente muy inclinada de tierra" (Varo 1999: 132). En Varo se da importancia a la movilidad a través del espacio compartido o espacio indefinido. Hay muchísimos más ejemplos: los límites entre el espacio público y el privado son poco tajantes en obras como Despedida (1958), Locomoción capilar (1959) y Mujer saliendo del psicoanalista (1960) (Kaplan 2000: 209, 157 y 154 respectivamente). En las tres, se está al mismo tiempo dentro de un edificio y deambulando por las calles de una ciudad.

Por otro lado, se ha sugerido que la arquitectura de Anglès, pueblo natal de Varo, aparece indirectamente en obras como las tres últimas. Aunque, como indica Isabel Castells, las ciudades de Varo nos suelen conducir al Medioevo (1999: 18-19), esto no impide reconocer las similitudes entre los espacios reales que habitara Varo y su representación en las obras mencionadas. Tal comparación es de particular importancia por la relación que se establece entre lo real y lo imaginario, y no deja de ser conflictiva, pues Varo solamente vivió en Anglès hasta 1913; tenía entonces alrededor de cinco años. En cualquier caso, aquí entra en juego el concepto de after-image no solamente en su dimensión de imagen que viaja (y cambia) a través del tiempo, sino también como elemento visual que reconcilia aquello real que se ha visto y aquello que el ojo de la mente percibe. En la obra de Varo, como diría Paz, "el tiempo madura" y permite representar un mundo que armoniza la relación entre contrarios, con 
ciudades, según Juliana González, "idealizadas" (en Varo 1969: 167). La omnipresencia del umbral cobra sentido.

\section{Análisis de Tránsito en espiral}

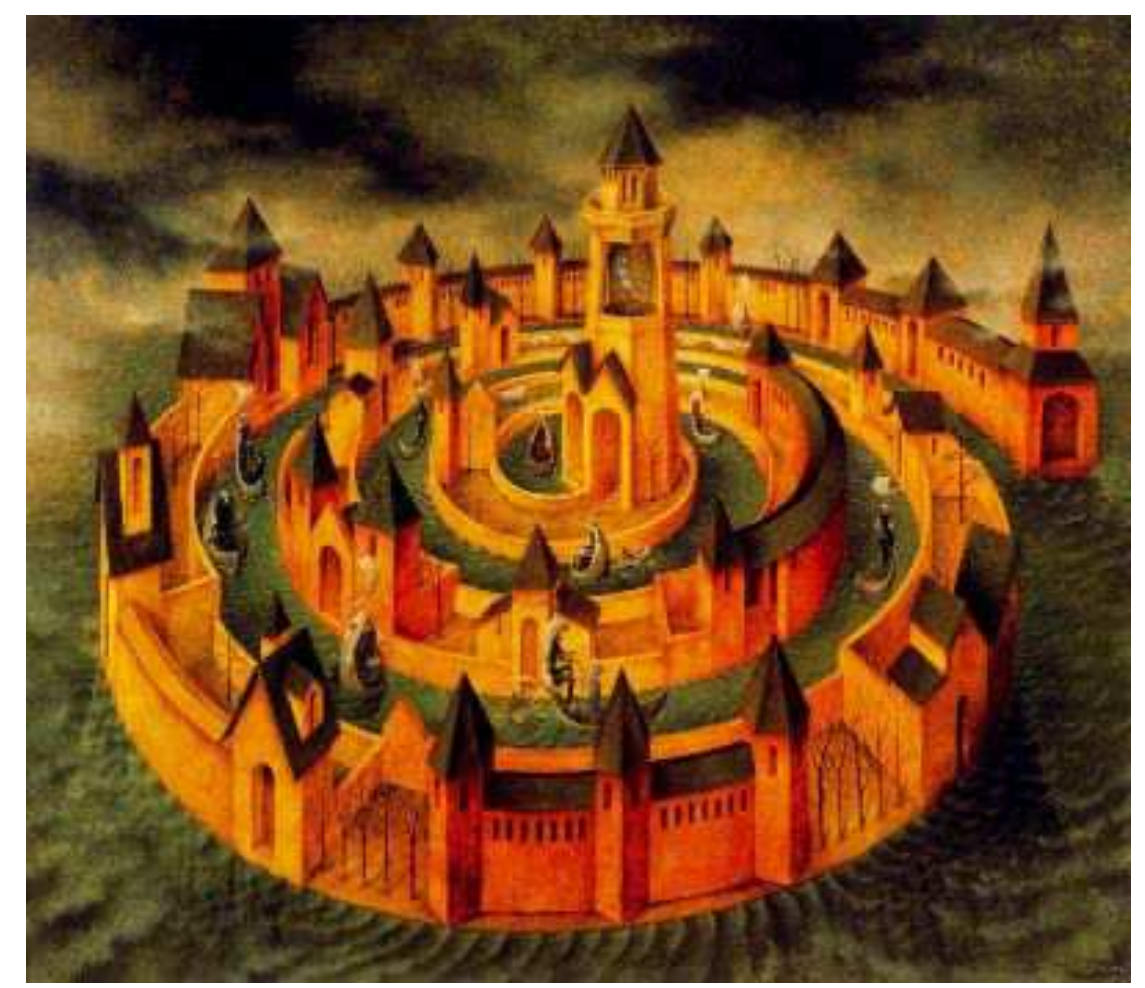

Figura 2. Tránsito en espiral (1962) @ Remedios Varo, DACS/VEGAP, 2013.

\subsection{La ciudad}

Tránsito en espiral (1962) (figura 2) se puede leer como ciudad heterotópica, ya que es un lugar ilusorio que contesta la típica distribución del espacio urbano moderno ${ }^{11}$. Se aprecian en esta obra diversas características de las ciudades antiguas (imaginarias o no) tal y como vienen explicadas por Chevalier y Gheerbrant: la ciudad antigua tenía que fundarse en una convergencia de vientos y aguas, de corrientes terrestres, y en consonancia con la luz y la oscuridad; según Platón, la capital de Atlantis estaba organizada en una serie de círculos concéntricos ${ }^{12}$; en el centro de las ciudades angkorianas se alzaba la Montaña, una imagen del monte Meru, centro y eje del mundo donde estaba el lingam real como en un templo; en la Edad Media se entendía la humanidad como un peregrino entre dos ciudades y la vida como un peregrinaje entre la ciudad de abajo y la

${ }^{11}$ Cabe señalar que, según Simón Marchán Fiz, la ciudad surrealista fue un espacio soñado e imaginario cuyos edificios llegaron a convertirse en "objetos encontrados" (apud Martín González 1986: 556).

12 Este círculo simbolizaría la perfección celestial (Chevalier y Gheerbrant 1996: 204), pero exploramos después la naturaleza superior de la espiral. 
ciudad de arriba; según el psicoanálisis contemporáneo, la ciudad es uno de los símbolos de la madre en su doble aspecto de protectora y controladora, siendo básicamente relacionable con el principio femenino (Chevalier y Gheerbrant 1996: 203-205). Todas estas características pueden observarse en mayor o menor medida en Tránsito, donde en general parecen celebrar la comunión de contrarios. Por ejemplo, la posible coexistencia de elementos masculinos y femeninos en el óleo enfatiza tal idea. Según Chevalier y Gheerbrant (1996: 203), la construcción de ciudades es un signo del asentamiento de las tribus nómadas, razón por la cual éstas solían construirse en cubos, símbolos de la estabilidad, y no circularmente como las tiendas nómadas y campamentos, símbolos del movimiento. Desde este punto de vista, la ciudad de Tránsito también se sitúa en un espacio liminar, pues combina la arquitectura urbana con la posibilidad de movimiento que marca la espiral.

\subsection{La espiral, la insularidad y el barco}

Kaplan destaca las similitudes entre esta obra y un dibujo alquímico de Goosen van Vreeswick (Kaplan 2000: 169-170). Sin embargo, las diferencias son notables al menos por lo que respecta al espacio, ya que en el dibujo de Vreeswick la espiral no incluye la ciudad sino que ésta se percibe al fondo de la imagen. La espiral de Varo, como forma perfecta por incluir un centro de transcendencia y una apertura al infinito, se opone a lo circular, que en su obra puede leerse en clave negativa como en Rompiendo el círculo vicioso (1962) (Kaplan 2000: 163). María Zambrano ilumina esta idea:

La espiral del ser. Los gnósticos se darán en espiral, en la que no hay reiteración; el círculo da la pobreza del ser, su economía indispensable. En el círculo no hay lugar para que los bienaventurados abran sus alas, ellos que son como pájaros impensables. Tampoco puede haber lugar para otros universos, otros pájaros, otras almas hijas del creador, además de las que ya conocemos. (cfr. Luquin Calvo 2008: 236)

Tránsito en espiral convierte la negatividad que pudiera relacionarse con la idea de tránsito (en Varo ocasionalmente reminiscente de su condición, entre otras cosas, de exiliada) con la espiral, que como se ha mencionado permite llegar a otros mundos alternativos habitados por otros seres. Aparece una especie de ciudad de estilo medieval con torrecillas distribuida en forma de espiral y entre los huecos de tal espiral se ve el agua de lo que se supone es el mar. Por lo tanto, no hay carreteras sino una especie de ríos y éstos son transitados por una variedad de medios de transporte maravillosos, vistos en otras obras de Varo y testimonio de su pasión por la tecnología (algo que su padre, que era ingeniero hidráulico, 
debió inculcarle) y, en especial, por el trabajo de Leonardo da Vinci. Se aprecian cinco animales blancos que semejan cabras montesas y once personas que en la mayoría de los casos no se sabe si son hombres o mujeres (excepto la pareja que aparece en la parte central inferior de la imagen). Cinco barcos (de carácter fantástico y algunos de los cuales tienen forma oval) van y cuatro vuelven de lo que parece ser el centro de la ciudad. No hay diferencias aparentes entre los que van y los que vuelven, sin embargo la dirección que toman determina la doble naturaleza de la espiral, pues se permite el movimiento en sentido del reloj y también al revés, es decir, esta espiral de Varo se puede leer como dextrógira o no. Dice Juan Eduardo Cirlot que "las antiguas tradiciones distinguían entre la espiral creadora (que se representaba dextrógira, atributo de Palas Atenea) y la destructora o torbellino (hacia la izquierda, atributo de Poseidón)" (Cirlot 2006: 202). Esto implica que la espiral de Tránsito combina fuerzas constructivas y destructivas: se puede seguir el camino de la sabiduría, pero al hacerlo habrá que enfrentarse a una serie de obstáculos. La forma de la espiral se hace eco del quinto principio de las heterotopías según Foucault, para quien estos espacios implican un sistema de apertura y clausura que las aísla y al mismo tiempo las hace penetrables. Entrar en este espacio, además, supone una obligación (como en el caso de las prisiones) o hace necesario pasar por un rito o una purificación (Foucault 1994: 759), que en Tránsito viene representada por el trabajoso viaje hacia el centro de la espiral. Además, tal y como observa Durand en referencia a Jones y a Baudouin, los lugares aislados, las islas, pueden representar la imagen mítica de la madre (Durand 1999: 232) y, por razones uterinas, lo que hace que un lugar sea sagrado es su clausura y esto incluiría a islas con simbolismo amniótico. La isla, así podría leerse la ciudad de Tránsito con sus calles acuáticas circuladas por barcos que también pueden entenderse como islas ${ }^{13}$, es un lugar sagrado que representa el arquetipo de la intimidad feminoide (Durand 1999: 238-239). Y es en el contexto de lo insular como refugio materno que Karl Philipp Moritz escribe: "A small Happy Isle on a stormy sea, fortunate is he who can sleep securely on its breast..." (apud Durand: 225).

A las presencias de los cinco barcos, se suma la ausencia representada por una especie de barco vacío, sin nadie que lo capitanee, al pie de la torre que corona el centro de la ciudad; suponemos que un ser, que ha llegado en barco, está en esa torre. En el centro de la torre se vislumbra un extraño pájaro ("lugar para [...] otros pájaros", decía Zambrano). Los colores que predominan son

13 El barco aparece como isla en miniatura atemporal en el poema "Le Lac" de Lamartine. Durand también interpreta este medio de transporte como cuna maternal (Durand 1999: 243). 
el dorado de la arquitectura, el blanco y el gris, producido éste último por el reflejo del cielo ennegrecido en el espejo de las aguas del mar. El dorado o el amarillo siena es un color muy importante en Varo, quien en su Sueño 3 lo define como "fuerza conciliatoria y determinante" (1999: 122). También dorados son un par de lazos que coronan dos de las embarcaciones fantásticas. Segun Cirlot, "se relacionan particularmente con la espiral los lazos y serpientes" (2006: 201).

Los árboles no tienen hojas y aparecen entre las torres, en varias ocasiones agrupados en cinco. El cielo señala tormenta. Es posible que este paisaje de clima difícil y naturaleza castigada corresponda a la idea de la vida como camino, como progreso, pero como un progreso con obstáculos y dificultades. Aunque esto, como bien indica Fernando Martín Martín, no se traduce en angustia:

En el universo pictórico de Remedios no hay sitio para el horror, la angustia o la agresividad [...]. Por el contrario, las historias prodigiosas que se nos cuentan, están presididas por la armonía y serenidad de las situaciones, sean de sorpresa o de carácter mágico. (Martín Martín 1988: 233)

Los reflejos en la parte inferior de la pintura que bordean la espiral parecen indicar que esta curiosa ciudad se desplaza. La gran diferencia con obras anteriores como El mundo del más allá (Trasmundo) (1955) (Kaplan 2000: 171), donde aparece un barcociudad, es que aquí el tránsito incluye la ciudad misma y así parece que el yo artístico ha conseguido una solución a sus problemas existenciales. En palabras de Cirlot, "la espiral es el intento por conciliar la 'rueda de las transformaciones'" (2006: 202). Y tan importante es la espiral para Varo que en su fragmento Mistress Thrompston descubre por casualidad el origen de la tremenda humedad que reina en el condado de Kent se refiere a la "cruz del Espiraloide Temporal" como la máxima condecoración posible (Varo 1999: 111). Tanto en Tránsito en espiral como en El mundo del más allá aparece el barco, cuya definición según Foucault es interesante. Pero no debe olvidarse la dureza del viaje al exilio que Varo experimentara en este medio de transporte, algo que se deja notar en menor medida en Tránsito a causa de la conciliación de la cual hablaba:

le bateau, c'est un morceau flottant d'espace, un lieu sans lieu, qui vit par lui-même, qui est fermé sur soi et qui est livré en même temps à l'infini de la mer et qui, de port en port, de bordée en bordée, de maison close en maison close, va jusqu'aux colonies chercher ce qu'elles recèlent de plus précieux en leurs jardins, vous comprenez pourquoi le bateau a été pour notre civilisation, depuis le XVIème siècle jusqu'à nos jours, à la fois non seulement, bien sûr, le 
plus grand instrument de développement économique [...] mais la plus grande réserve d'imagination. Le navire, c'est l'hétérotopie par excellence. Dans les civilisations sans bateaux les rêves se tarissent, l'espionnage y remplace l'aventure, et la police, les corsaires. (Foucault 1994: 762)

En efecto, en Tránsito los nueve barcos que aparecen se pueden entender como las más grandes reservas de la imaginación, sin ellos no sería posible llegar al centro de esta ciudad cósmica que nos presenta Varo $y$, por lo tanto, sin su presencia no habría sabiduría entendida en su sentido más primigenio. Es decir, sin imaginación no hay conocimiento. Ésta es, por ejemplo, la misma concepción que desarrolla Dalí al entender la importancia de las matemáticas y la física, entre otras disciplinas, en la producción artística. O lo mismo que Max Ernst persigue en sus aplicaciones no euclídeas. Con los barcos, se mantiene la posibilidad de sueño y aventura, incluso en situaciones adversas. Es más, la idea del barco como heterotopía también afecta a la ciudad-espiral del óleo de Varo, que como se ha visto también está en movimiento y representa un lugar sin un lugar "qui est fermé sur soi et qui est livré en même temps à l'infini de la mer" (Foucault 1994: 762).

\section{La androginia y el tiempo}

En bastantes ocasiones, los personajes de Varo resultan difíciles de definir desde el punto de vista del género -Doble Agente (1936), Ser andrógino (1957), Encuentro (1959) $-^{14}$. En estas obras se aprecia que Varo trata de crear un nuevo mundo donde los valores femeninos y masculinos están sintetizados en un ideal andrógino. Este deseo por volver al mundo primigenio encaja con los ideales alquímicos pero también con la definición de heterotopías, pues éstas también tienen el potencial de contestar los valores tradicionales coetáneos (Foucault 1994: 759) ${ }^{15}$. También hay heterotopías de "temps qui s'accumule à l'infini" (Foucault 1994: 759). Esto se aprecia en obras de Varo que acumulan elementos relativos a diferentes momentos históricos como La revelación o el relojero (1955) (Kaplan 2000: 175), donde, en palabras de Varo, "hay cantidad de relojes que marcan todos la misma hora, pero dentro de cada uno hay el mismo personaje en

14 En el caso de Ser andrógino se aprecia una figura femenina con sombra masculina (cfr. Asociación "Ayúdale a Caminar" 2009). Doble agente y Encuentro aparecen respectivamente en las páginas 49 y 152 de Kaplan (2000).

${ }_{15}$ Fernando Martín Martín indica que "surrealismo y alquimia descansan sobre un mismo principio, esto es, son fundamentalmente un medio que tiene como objeto la transformación y el cambio" (1988: 237-238). Sin embargo, el concepto de la heterotopía confiere a esta ecuación, por la que conseguimos aproximarnos a la obra de Varo, una más clara voluntad de llegar a la realización personal. De ahí su importancia. 
muy diferentes épocas; eso lo consigo por medio de los trajes característicos de épocas muy distintas" (apud Luquin Calvo 2008: 240). La obra de Varo puede relacionarse con la teoría del tiempo psicológico fluido de Henri Bergson o incluso con la teoría de la relatividad, según la cual, como sugiere Andrea Luquin, el tiempo es un elemento del espacio (Luquin Calvo 2008: 242). Yo añadiría que los umbrales que observamos en La revelación o el relojero permiten una espacialización, tanto física como psicológica, del tiempo.

\section{Conclusiones}

En conclusión, se aprecia en las obras de Varo una tensión por superar la división entre sujeto y objeto. La imagen de la ciudad en la obra de la artista es, lejos de una cuestión trivial, un indicador de los componentes de la ciudad ideal, entre los cuales destaca la presencia del limen entre lo natural y lo sobrenatural, entre el interior y el exterior, entre lo real y lo fantástico, entre el mundo de los sueños y el mundo consciente. La ciudad variana es un espacio que permite la comunicación constante entre los contrarios. De este modo, la liminalidad entre aquello que es urbano y aquello que no lo es también resulta esencial para entender la postura estético-biológica de la artista. Las ciudades de Varo están repletas de umbrales e implican un cuestionamiento de los lugares como espacios separados.

La pintora no se limita a mostrar un gusto inocente por la esencia de la ciudad, como Joan Salvat-Papasseit en Poemes en ondes hertzianes (1919) y L'irradiador del port i les gavines (1921), o una queja ante la naturaleza violenta e inhumana de la misma, como Federico García Lorca en Poeta en Nueva York (1929). Varo no se detiene en la observación estética o en plasmar un disgusto por lo urbano, ella nos presenta una opción de escape, una solución a la desolación: un nuevo mundo, con nuevas ciudades, de modo muy similar a Un mundo (1929) de Ángeles Santos. Para Luquin, en Varo (como también en Giorgio de Chirico) existe un "tiempo retenido en los espacios", pero la diferencia entre ambos reside en la ausencia de una representación de la destrucción en la obra de la artista (2008: 188-89). En este sentido, tal representación de lo urbano se relaciona con la agencia femenina y la implicación de la mujer en la consecución de un orden cósmico más habitable. 


\section{Bibliografía}

Asociación "Ayúdale a Caminar" (2009): Ciudad de la Pintura [en línea]. Madrid: Asociación "Ayúdale a Caminar", 5 de febrero de 2009. En: http://pintura.aut.org/SearchProducto?Produnum=61597 [Consulta: $15 / 03 / 2013]$.

BRETON, André (1972a): "Manifesto of Surrealism" (1924), en Richard Seaver y Helen R. Lane (trads.), Manifestoes of Surrealism, pp. 1-47. University of Michigan Press: Ann Arbor Paperbacks.

- (1972b): "Second Manifesto of Surrealism" (1930), en Richard Seaver y Helen R. Lane (trads.), Manifestoes of Surrealism, pp. 117-187. University of Michigan Press: Ann Arbor Paperbacks.

CHADWICK, Whitney (1985): Women Artists and the Surrealist Movement. Londres: Thames and Hudson.

CHEVALIER, Jean; y GHEERBRANT, Alain (1996): A Dictionary of Symbols. Traducción de John Buchanan-Brown. Londres: Penguin Books.

CIRLOT, Juan Eduardo (2006): Diccionario de símbolos. Madrid: Siruela.

DE DIEGO, Estrella (2007): Remedios Varo. Madrid: Fundación MAPFRE / Instituto de Cultura.

DERIU, Davide (2006): "The Ascent of the Modern Planeur: Aerial Images and Urban Imaginary in the 1920s", en Christian Emden, Catherine Keen y David Midgley (eds.), Imagining the City, pp. 189-211. Bern / Oxford: Peter Lang.

DREISER, Theodore (1970): Sister Carrie. Edición de Donald Pizer. Nueva York: W. W. Norton.

DURAND, Gilbert (1999): The Anthropological Structures of the Imaginary. Traducción de Margaret Sankey y Judith Hatten. Brisbane: Boombana Publications.

EVERLY, Kathryn A. (2003): Catalan Women Writers and Artists: Revisionist Views from a Feminist Space. Lewisburg, PA: Bucknell University Press / Londres: Associated University Presses.

FÀBREGA, Jaume et al. (1988): Surrealisme a Catalunya 1924-1936: de I'Amic de les Arts al Logicofobisme. Barcelona: Edicions Polígrafa.

FOUCAULT, Michel (1994): "Des espaces autres", en Daniel Defert y, François Ewald (eds.), Dits et écrits 1954-1988, pp. 752-762. París: Éditions Gallimard, 4 vols.

GRANELL, Eugenio F. (1988): "La selva salvada de Remedios Varo", en Remedios Varo, pp. 65-66. Madrid: Fundación Banco Exterior.

IRIGARAY, Luce (1985): This Sex Which Is Not One. Traducción de Catherine Porter. Nueva York: Cornell University Press.

KAPLAN, Janet A. (2000): Remedios Varo: Unexpected Journeys. Nueva York / Londres: Abbeville Press.

LUQUIN CALVO, Andrea (2008): Remedios Varo: el espacio y el exilio. San Vicente del Raspeig [Alicante]: Centro de Estudios sobre la Mujer / Universidad de Alicante.

MARTÍN GONZÁLEZ, Juan José (1986): "Reseña de Contaminaciones figurativas: imágenes de la arquitectura y la ciudad como figuras de lo moderno de Simón Marchán Fiz". Boletín del Seminario de Estudios de Arte y Arqueología: BSAA, núm. 52, pp. 555-556. 
MARTÍN MARTÍN, Fernando (1988): "Notas a una exposición obligada: Remedios Varo o el prodigio revelado". Laboratorio de Arte, núm. 1, pp. 231-246.

RESINA, Joan Ramon (2003): "The Concept of After-Image and the Scopic Apprehension of the City", en Joan Ramon Resina y Dieter Ingenschay (eds.), After-Images of the City, pp. 1-22. Ithaca y Londres: Cornell University Press.

JOHNSON, Sam (2013): The M. C. Escher Site [en línea]. Área de la Bahía de San Francisco: Sam Johnson, 4 de marzo de 2013. En: http://eschersite.com/eschersite/Covered Alley Escher 150.html [Consulta: 15/03/2013].

THARRATS, Joan-Josep (1993): Surrealisme a l'Empordà $i$ altres fantasies. Barcelona: Parsifal Edicions.

VARO, Remedios (1969): Remedios Varo. Edición de Roger Caillois y Octavio Paz. México: Ediciones Era.

- (1999): Cartas, sueños y otros textos. Introducción y notas de Isabel Castells. México: Ediciones Era.

VÀZQUEZ, Eva (2004): "Remedios Varo al país de les metamorfosis". Revista de Girona, vol. 227, pp. 48-57.

WILSON, Elizabeth (2002): "The Sphinx in the City: Urban Life, the Control of Disorder, and Women", en G. Bridge y S. Watson (eds.), The Blackwell City Reader, pp. 419-429. Oxford: Blackwell. 